\title{
Fabrication and Catalytic Properties of Co-Ag-Pt Nanoparticle Decorated Titania Nanotube Arrays
}

Lixia Yang, Dongmei He, Qingyun Cai ${ }^{*}$

State Key Laboratory of Chemo/Biosensing and Chemometrics, Department of Chemistry, Hunan University, Changsha 410082, China

Craig A. Grimes

Department of Electrical Engineering, and Department of Materials Science and Engineering, The Pennsylvania State University, University Park, Pennsylvania 16802 USA

\footnotetext{
* Corresponding author. E-mail: qycai0001@ @nu.cn
} 
Supporting Information:
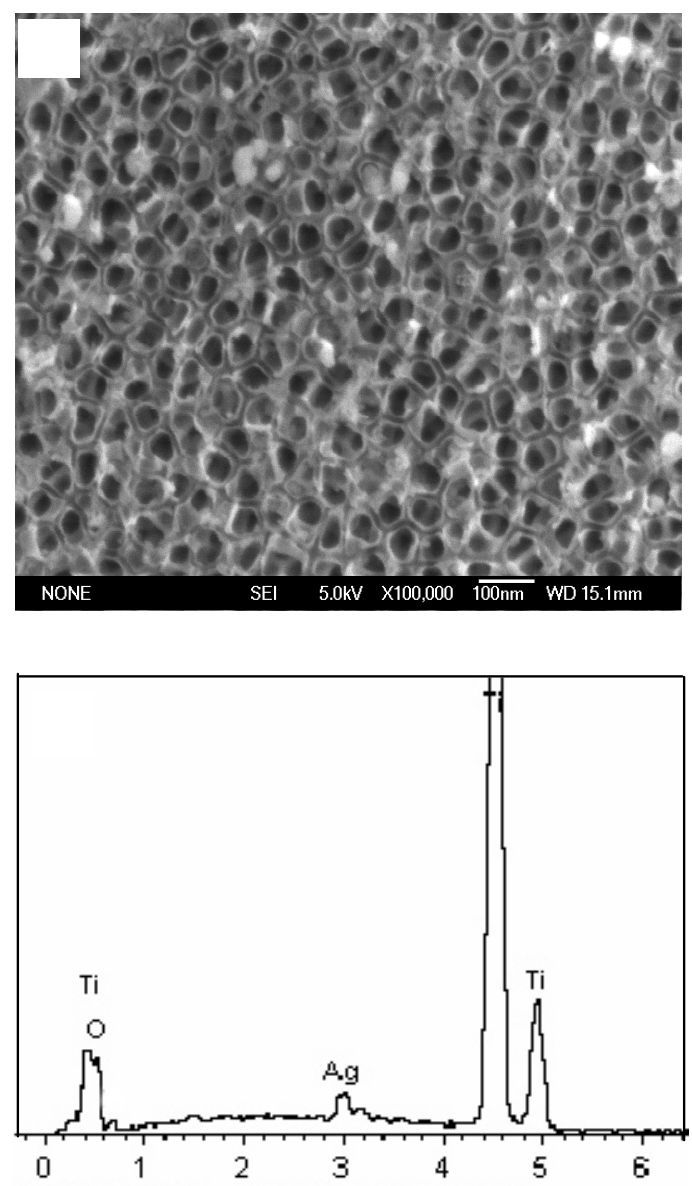


\section{Table S1}

Concentrations of each elements present on the Ag/titania nanotubes in Figure S1(a).

\begin{tabular}{lll}
\hline Element & $\begin{array}{l}\text { Weight } \\
\text { percentage }\end{array}$ & $\begin{array}{c}\text { Atom number } \\
\text { percentage } \\
\text { Ti K }\end{array}$ \\
66.74 & 43.58 \\
O K & 28.03 & 54.91 \\
Ag L & 5.23 & 1.51 \\
\hline
\end{tabular}

